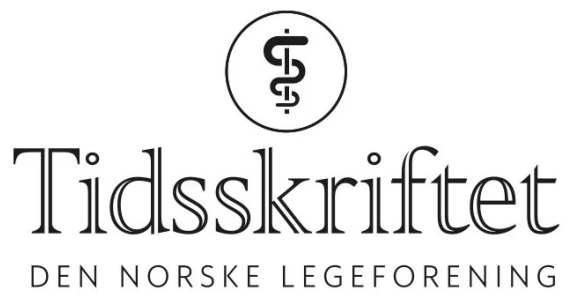

\title{
Den siste mohikaner
}

INTERVJU

CHARLOTTE LUNDE

charlottelunde@me.com

I kampen mot et stadig mer produksjonsstyrt helsevesen er han klinikernes kriger i landets mektigste sykehusstyre. En krig han innerst inne egentlig tror er tapt. 


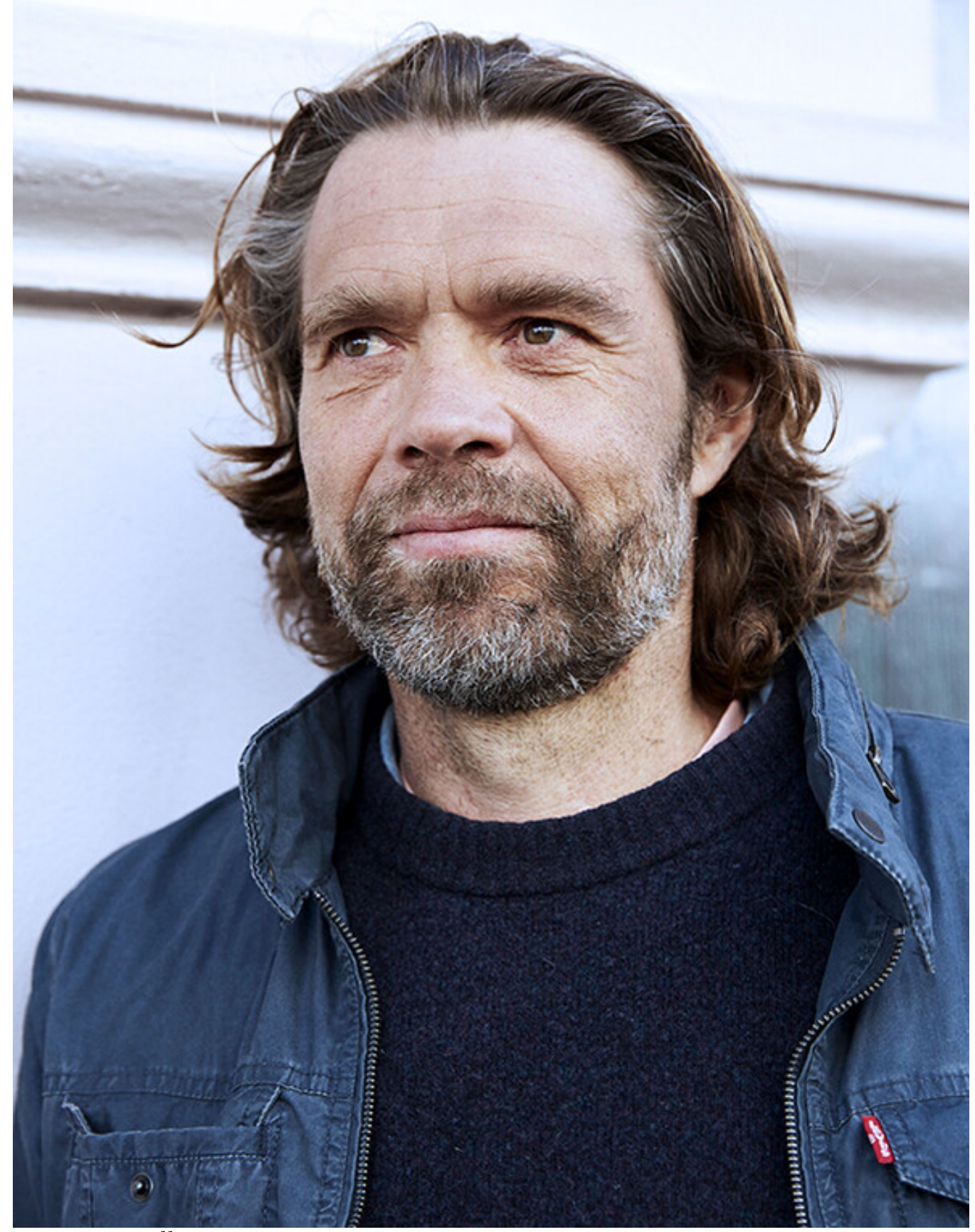

Foto: Birgit Solhaug

- Hm... ja, det er nok mest sannsynlig, men hvem vet hvor haren hopper? spør Christian Grimsgaard, konserntillitsvalgt i Helse $§ ø r-\emptyset$ sts styre.

Kledd i blå jakke, olabukser og tursko sitter han på en benk på Bygdøy en kjølig lørdag i mars. Han har ikke tenkt å gi seg, men mener flere leger burde engasjere seg, hvis vi skal klare å snu retningen sykehusene går i.

- Jeg opplever vel at det er veldig sterke krefter i sving for å kappe land innenfor helsefeltet. Management-tankesettet fortrenger fag. Mitt mandat er å krige litt på vegne av alle de som er der ute i klinikken i en verden som innimellom er ganske vulgær, sier 51-åringen. Han sikter til topplederskapet i dagens helsevesen, og ordet målstyring er ikke et favorittord i denne kirurgens vokabular. 
- Grunnen til at jeg orker å stå i det er at jeg har ingen ambisjoner i dette systemet. Det er vel en rabulist i meg der, medgir Grimsgaard. Han smiler skjevt. Intervjuet foregår ute i tråd med gjeldende smittevernforskrifter, og kaffen serveres fra medbrakt termos.

Vi åpner med å påpeke at han er fra en legefamilie gjennom mange generasjoner. Googler vi navnet Christian Grimsgaard dukker det nemlig opp en lege som døde i 1895.

- Ja, det er en familie med mange Christian Grimsgaarder, sier han nølende og tar en slurk av kaffen.

Ordene kommer ikke like spontant som når han snakker om New Public Management, eller virksomhetsstyring som det nå heter. At han er fra en tradisjonsrik legefamilie er ikke det han er mest opptatt av å utdype, men han svarer høflig.

- Sønnen min har fått både et annet for- og etternavn enn meg for å si det sånn, understreker han. Sønnen på 20 år studerer foreløpig ikke medisin. Selv forsøkte Grimsgaard å bryte familietradisjonen ved å søke i en mer filologisk retning ved å begynne på grunnfag i litteraturvitenskap på Blindern.

- Det var jo et spørsmål om jeg skulle velge medisin eller noe annet? Skulle jeg gå i mine foreldres fotspor eller ikke? spør han ut i luften. Han lar blikket følge en fugl over himmelen og tar en liten pause før han svarer seg selv:

- Men sånn ble det ikke. Jeg endte med å følge i mine foreldres fotspor.

Konformitet er likevel ikke det første som slår en når man undersøker denne ortopedens biografi, selv om begge foreldrene var leger. Han benekter at det er noen ambivalens i valget, og understreker at han er glad for at det ble medisin.

\section{«På 7o-tallet hadde man en tro på at vi beveget oss mot noe bedre. Nå er} det litt tynnere vilkår for de idealene»

- Men jeg har jo alltid vært glad i ord, legger han til. Venner har avslørt at han har «et håvamål for enhver anledning». Han trekker på det.

- Jeg vet ikke det akkurat, men jeg har fraser som kan surre rundt i hodet. For eksempel er det en frase fra en sang jeg liker: «jeg jakter ikke på ambisjoner jeg allikevel ikke har», gjengir Grimsgaard. Vi ber han utdype:

- Det er vel egentlig et uttrykk for at du ikke jakter på ting eller posisjoner du ikke er interessert i. Jeg tror mange faller inn i et spor der de blir styrt av ytre hensyn, det å ha en fin hage, sier han underfundig.

«Hvem har skrevet det?» spør vi som ikke kan vår Edda utenat.

Han gliser:

- Et dansk rapband fra 9o-tallet kalt Østkyst Hustlers. Hyggelig gammalmannshiphop, legger han til.

\section{En himmel full av stjerner}

Den systemkritiske holdningen fikk kanskje sin start under 7o-tallsoppveksten i Oslo. I et slags psykiatriens Bakkebygrenda tilbrakte han barndommen. I et brunt rekkehus, en ansattbolig tilhørende Gaustad sykehus, var det ofte fagpolitiske diskusjoner rundt middagsbordet. Moren var overlege og en av behandlerne involvert i den mye omtalte Arnold Juklerød-saken. Grimsgaard husker de kunne bli oppringt av journalister midt på natten som skulle ha kommentarer fra moren.

\section{Christian Grimsgaard}


Studentvikar, Allmennseksjonen, Oslo Legevakt 1996-99

Turnus, Sykehuset i Vestfold 1998-99

Distriktsturnus, Harstad 1999

Assistentlege, Ortopedisk avdeling, Tønsberg 2000

Assistentlege, Ortopedisk avdeling, Bærum sykehus 2002

Assistentlege/overlege, Ortopedisk avdeling, Rikshospitalet håndkirurgisk seksjon 2004-

d.d.

Tillitsvalgt, klinikk for kirurgi og nevrofag, Oslo universitetssykehus 2010

Vara-foretakstillitsvalgt, Oslo universitetssykehus 2013-2016

Konserntillitsvalgt, Helse Sør- Øst 2016-d.d.

Styremedlem, Norsk overlegeforening 2011-d.d.

Styremedlem, Legeforeningens sentralstyre 2013-2016

Styremedlem, Helse Sør-Øst 2017-d.d.

- Det var jo en interessant sak i brytningspunktet mellom individets rettigheter og fagmakt, men jeg husker at de involverte behandlerne følte seg litt maktesløse, forteller han.

Tiden var preget av idealisme og en reformvennlig psykiatri.

- Det var et livlig sted å vokse opp. Det var jo et helt samfunn med over 7oo innlagte og mange bodde der over lang tid. Det var frisør der og et eget 1. mai-tog. Tenk at det gikk et eget 1. mai-tog fra Gaustadveien?

Det er lett å høre entusiasmen i stemmen. Syttitallets radikale optimisme fascinerer han.

- På skolen satt vi og sang «En himmel full av stjerner» og «Herr President». Vi hadde en visjon for et bedre samfunn. Idealene om en bedre verden var nok litt mer intakte på den tiden. På 7o-tallet hadde man en tro på at vi beveget oss mot noe bedre. Nå er det litt tynnere vilkår for de idealene, tror Grimsgaard.

Han er likevel opptatt av å understreke at «ikke alt var bedre før» og at mye også er bedre nå. Han utelukker ikke at det bor en romantisk idealist i han. Kanskje ikke tilfeldig at også Shakespeares Hamlet da står på listen over tekster han kan gruble over.

- I åpningsmonologen reflekterer Hamlet rundt «Hva er edel ferd?». Skal du akseptere eller forsone deg med verden som den er? Skal du gjøre et opprør eller skal du ende det, ta livet ditt? Det er jo de dilemmaene som diskuteres i den monologen. Det er også relevant i min jobb som tillitsvalgt. Hvilke kamper er det jeg skal gå inn i, reflekterer kirurgen. 


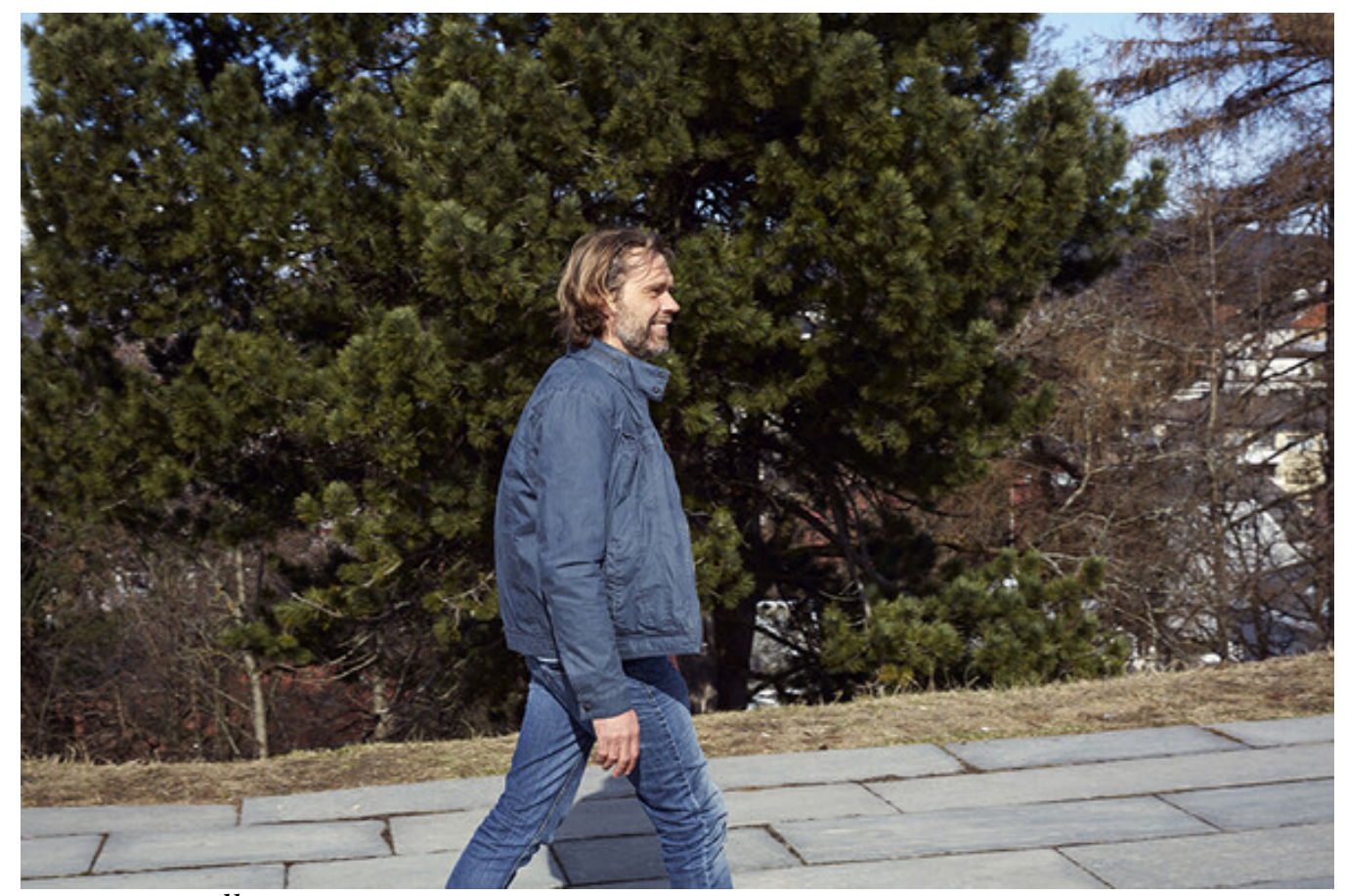

Foto: Birgit Solhaug

- Sykehusledelse er rett og slett shakespearsk maktkamp? Like råttent som staten

Danmark?

- Ja, det kan det være. Men jeg har hatt mange morsomme samtaler med sykehusledere om dette. Hamlets tragedie er at han er et dannet menneske i en primitiv verden. Det danske hoffet er middelaldersk: brutalt og vulgært. En fyr som Hamlet, bundet av humanisme og renessanseidealer, faller helt igjennom. Den problematikken er jo like relevant i dag. Vi ser ofte vulgære folk dominere verden, mens folk som er drevet av et bedre verdisett og målsettinger bare blir overkjørt. Det er min opplevelse av ganske mye av det vi driver med som tillitsvalgte også.

\section{En underdog eller en Trump}

Bevæpnet med Hamlet og dansk hiphop til tross, også Grimsgaard kan la seg målbinde.

- Jeg var i en diskusjon med en leder en gang hvor jeg påpekte at selv om han var en vennlig fyr kunne han i kraft av lederrollen sin fremstå som skummel for noen. Da pekte han på meg med dirrende pekefinger og sa: «Jeg skal si deg en ting jeg, Christian: Folk er redde for deg også!».

Grimsgaard ler. Det var en helt ny tanke at han selv kunne virke truende.

- Jeg ble gående å tenke litt på det. Kanskje han hadde rett? Jeg har jo alltid sett på meg selv som en underdog som ikke har makt, men som alltid skal prøve å jobbe for å bevege de folka som faktisk har makt. Men det er kanskje ikke sånn de ser på meg? Det kan jo være at de tidvis opplever meg som en pamp av en tillitsvalgt. Det har kanskje vært en strategi, det å ta litt plass, være litt direkte og konfronterende. Men det er alltid med medlemmenes mandat, legger han raskt til. Ryktet forteller likevel at han selv ble kalt Trump av styreleder på siste styremøte i Helse $\ ø r-\emptyset$ st.

"Det er en grunn til at Oslo universitetssykehus er Europas største

sykehus. Det er ingen andre i Europa som har kommet opp med en så dårlig idé!» 
- Hehe, ja, det stemmer faktisk... Jeg blir jo irritert, men svarer på en ryddig måte. Det er nok et uttrykk for at det er ganske anstrengt stemning i en del av diskusjonene man står i. Man kan bli utsatt for karakteristikker og ikke-verbal hersketeknikk. Det er ikke alle som bevarer fatningen til enhver tid.

- Er du selv hissig?

- Det kan nok være at jeg også gir uttrykk for utålmodighet. Jeg er en sånn type folk ikke liker å gå på kino med, fordi jeg sitter ofte og vrir meg i stolen og lager gutturale lyder.

- Gjør du det på styremøter?

- Tja... jeg kan nok det, innrømmer konserntillitsvalgt i HSØ-styret med et smil.

- Du tisser ikke i vasken når du blir irritert nok?

Han ler godt.

- Nei, det har jeg ikke gjort.

Historien om hjertekirurgen som i hissig protest forlot et strategimøte på Rikshospitalet med å tisse i vasken fordi han ble bedt om å stumpe røyken, er legendarisk. Den tilhører likevel en annen tidsregning - og møteadferd - enn den man finner i dag.

- De var jo ganske underholdene de gutta der, og det var en tid med litt mer mangfold kan du si. Det er nok blitt litt mer pertentlig på kirurgen nå, slår Grimsgaard fast.

\section{Et tapt tiår}

I rundt ti år har håndkirurgen fra Rikshospitalet vært en sentral motstemme i striden rundt Oslo universitetssykehus. Dette fikk han også prisen «Oslo-legen» for i 2011.

- Det er en grunn til at Oslo universitetssykehus er Europas største sykehus. Det er ingen andre i Europa som har kommet opp med en så dårlig idé! Det er jo ingen gevinst i å forsøke å gjøre tre fungerende biler til en buss ved å sette dem oppå hverandre, sier han engasjert. 


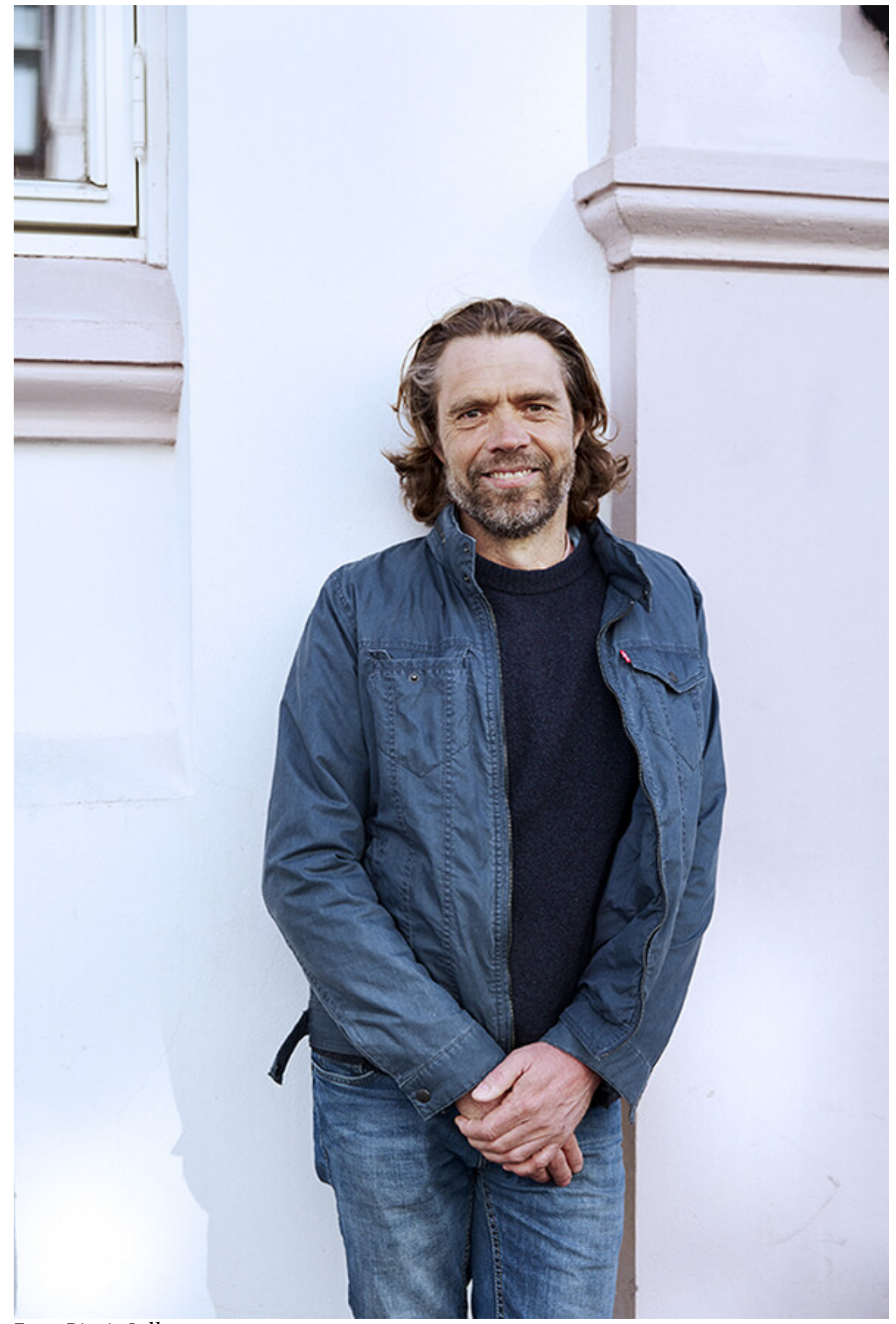

Foto: Birgit Solhaug

Kilder bekrefter at dette engasjementet også har bidratt til flere sykehusdirektørers fall, uten at han ønsker å kommentere det direkte.

- Oslo-sykehusene hadde en fornuftig organisering med et lokalsykehus, et spesialistsykehus og et akuttsykehus. Det var ikke opplagt at det kunne gjøres veldig mye bedre. Jeg hadde selv jobbet klinisk på sykehus av ulik størrelse og sett litt hvordan ting fungerte. Så når man da gikk løs på det man hadde med hammer og slegge uten en konkret plan om hva man ville gjøre, fremsto det som veldig dårlig gjennomtenkt, konstaterer Grimsgaard. Han fortsetter: 
- Jeg mener dette har vært et tapt tiår for Oslo-sykehusene. Sammenslåingen har gjort driften kjempekrevende og vi har havnet i en bakevje med en organisasjon som om vi driver ett sykehus. Det gjør vi jo ikke. Vi står fremdeles med tre sykehus og en altfor stor organisasjon, sier han oppgitt.

\section{Harde endepunkter}

Tar du sykehusstriden fra denne mannen tar du kanskje også lykken fra han med det samme.

- Liker du å være i opposisjon?

- Ja, kanskje. Jeg er opptatt av brytning. Du må ha meningsbrytning og en diskusjon om hvor veien skal gå. Alt er en avveining og hvis man ikke drøfter det med ulike perspektiver går det ikke bra, mener Grimsgaard.

- Jeg har nok en offensiv holdning. Jeg påpeker ofte at folk mangler forankring og innsikt i det de snakker om. Det er jo spesielt å sitte i et styre i et helseforetak uten noen som helst bakgrunn fra helsevesenet? Jeg ville jo aldri satt meg i styret til Norges Bank og begynt å plapre. Du lar ikke tonedøve styre et symfoniorkester, akkurat som det ikke er noe kall å bli samfunnsøkonom, påpeker Grimsgaard bestemt.

\section{«Vi måler overlevelse og liggetid.Vi måler ikke den mest avanserte \\ dimensjonen av alle: At vi tar vare på folk og møter dem på en respektfull måte»}

Tretti år etter at begrepet New Public Management dukket opp, mener han at "sykehusene har skrumpet inn både i ånd og i form». Han er enig i Fredrik Holsts formulering fra 1827 om at sykehusene på mange måter er målestokken for et folks sivilisasjon.

- De sykehusene man etablerte i forrige århundre var avanserte ikke bare teknisk sett. De var også avanserte ved at de bygget inn en omsorgsdimensjon basert på humanistiske idealer som et tydelig formål for tjenesten. Det er man i ferd med å bryte ned. Formålet er endret. Hvor er omsorgsdimensjonen i dagens sykehus? Hvor er det den rapporteres? Vi måler overlevelse og liggetid. Vi måler ikke den mest avanserte dimensjonen av alle: At vi tar vare på folk og møter dem på en respektfull måte. Målstyring uthuler det som er bra. Det er blitt harde endepunkter i alt. Det er der krigen står nå, slår han fast.

Han tror legene ikke er helt klar over at de er i ferd med å tape terreng i denne kampen. Han tar en siste slurk av kaffen som har rukket å bli kald.

- Tida vår er tilmålt. Du må hele tiden gjøre valg og justere kurs. Det gjelder ikke bare i helsepolitikk, men generelt i livet. Veldig mange faller bare inn i et spor og blir der uten å tenke over hvorfor, sier Grimsgaard. Han innrømmer at han tidvis «veksler mellom å tro og å gi opp». Han tror likevel at nettopp i velferdsstaten Norge er det mulig å få til et bedre fungerende helsevesen enn det vi har.

- Vi har jo egentlig ordna oss så bra. I utgangspunktet har vi et veldig godt system, men vi må jobbe bedre for et felles prosjekt, en overbygning. Hvis ikke blir alt bare en Mad Maxverden. Du må rett og slett ha en høyere himmel, avslutter han.

Publisert: 6. mai 2021. Tidsskr Nor Legeforen. DOI: 10.4045/tidsskr.21.0279

(C) Tidsskrift for Den norske legeforening 2023. Lastet ned fra tidsskriftet.no 26. april 2023. 